\title{
Correlation between the development of calcium oxalate stones and polymorphisms in the fibronectin gene in the Uighur population of the Xinjiang region of China
}

\author{
M. Murat' ${ }^{1}$, A. Aekeper ${ }^{1}$, L.Y. Yuan ${ }^{1}$, T. Alim¹, G.J. Du ${ }^{1}$, A. Abdusamat ${ }^{1}$, \\ G.W. $\mathbf{W u}^{1}$ and Y. Aniwer ${ }^{2}$ \\ 1'Department of Urology, The Second Affiliated Hospital of Xinjiang Medical, \\ University, Urumqi, Xinjiang, China \\ ${ }^{2}$ Department of Urology, The First Affiliated Hospital of Xinjiang Medical University, \\ Urumqi, Xinjiang, China \\ Corresponding author: Y. Aniwer \\ E-mail: xjammt_!@163.com
}

Genet. Mol. Res. 14 (4): 13728-13734 (2015)

Received May 19, 2015

Accepted July 14, 2015

Published October 28, 2015

DOI http://dx.doi.org/10.4238/2015.October.28.35

ABSTRACT. Here, we have investigated the correlation between calcium oxalate stone formation and $F n$ gene polymorphisms in urinary calculi patients among the Uighur population (Xinjiang region). In this case control study, genomic DNA extracted from the peripheral blood of 129 patients with calcium oxalate stones (patient group) and 94 normal people (control group) was used to genotype polymorphisms in the rs6725958, rs 10202709 , and rs 35343655 sites of the $F n$ gene by polymerase chain reaction-restriction fragment length polymorphism. Subsequently, the association between different genotypes and susceptibility to calcium oxalate stone formation was compared among the patient and control groups. Single nucleotide polymorphisms (SNPs) were detected in the rs6725958, rs10202709, and rs35343655 sites of the Fn gene among the patient and control groups. The genotype distributions of the three 
loci complied with the Hardy-Weinberg equilibrium. The results of allele frequencies of the patient/control group for polymorphisms in the rs 6725958 site of the $F n$ gene were $C=179(69.92 \%) / 119(63.30 \%)$ and $A=77$ $(30.08 \%) / 69(36.70 \%)$, in the rs 10202709 site were $\mathrm{C}=245(95.70 \%) / 176$ (93.63\%) and $\mathrm{T}=11(4.30 \%) / 12(6.38 \%)$, and in the $\mathrm{rs} 35343655$ site of the Fn gene were $A=139(54.30 \%) / 87(46.28 \%)$ and $\mathrm{G}=117(45.70 \%) / 101$ (53.72\%). We observed no significant differences between the three SNPs and development of calcium oxalate stones. Polymorphisms in rs6725958, rs10202709, and rs35343655 of the Fn gene had no obvious effect on the susceptibility to the development of calcium oxalate stones in the Uighur population, residing in the Xinjiang region of China.

Keywords: Calcium oxalate stones; Fibronectin; Gene polymorphism; Uighur

\section{INTRODUCTION}

Urinary calculi is a common disease affecting humans worldwide, and is one of the three major diseases affecting the urinary system. Approximately $10 \%$ of the population suffers from urinary calculi, with $70 \%$ of these cases exhibiting the development of calcium oxalate stones. The latter represents the idiopathic form of the disease with no clear genetic background and relatively systemic diseases, clinically (Deng et al., 2009; Worcester and Coe, 2010). The recurrence rate of urinary calculi remains high despite the considerable progress in the design of therapeutic strategies for the same (Brikowski et al., 2008). The exact mechanism of urinary calculi remains unclear because of the complicated etiology related to living habits, natural environment, and inheritance. In addition, there are significant regional and racial differences in the etiology (Soucie et al., 1994). Polymorphisms in the ficronectin gene $(F n)$ were analyzed and compared along three sites (rs6725958, rs10202709, and rs35343655) between patients displaying the presence of calcium oxalate stones and healthy people, using polymerase chain reaction-restriction fragment length polymorphism (PCR-RFLP). In addition, we studied the correlation between the development of calcium oxalate stones and the $F n$ gene polymorphisms in the Uighur population of the Xinjiang area in China.

\section{MATERIAL AND METHODS}

\section{Study subjects}

This retrospective study analyzed information regarding 129 unrelated (by blood) Uighur patients (average age $43 \pm 10$ ) with urinary calculi, diagnosed based on clinical symptoms, and X-ray plain film and B-mode analyses. All patients were operated in the hospital, or received extracorporeal shock-wave lithotripsy (ESWL) treatment; the samples were determined to be composed of calcium oxalate stones. The control group was comprised of 94 healthy volunteers (average age $46 \pm 9$ ) without a history of urinary calculi. Patient and volunteer information was obtained from the Department of Urinary Surgery of the First Teaching Hospital of Xinjiang Medical University and the Second Affiliated Hospital of Xinjiang Medical University. There were no significant differences in the sex and age between the case and control groups ( $P>0.05)$. 
Written approval for the study was obtained from the institutional review board of the First Teaching Hospital of Xinjiang Medical University and the Second Affiliated Hospital of Xinjiang Medical University. Informed consent was obtained from all patients and controls.

\section{Methods}

\section{Genomic DNA extraction}

Blood samples $(2 \mathrm{~mL})$ were drawn from the antecubital vein of the members of the case and control groups; the samples were stored in ethylene diamine tetraacetic acid (EDTA) at $-20^{\circ} \mathrm{C}$. DNA was extracted using the blood genomic DNA extraction kit (K5017500; BioChain Science \& Technology, Inc., Beijing, China). The integrity of the genomic DNA was analyzed by agarose gel electrophoresis.

\section{PCR amplification}

The PCR primers were obtained from BBI Life Sciences Corporation, 01035.HK. The primer sequences used for the amplification of specific sites on the Fn gene are listed in Table 1. Specific DNA sequences were amplified by PCR in vitro in a $15 \mu \mathrm{L}$ reaction system (composition of the system is summarized in Table 2). The reaction conditions for PCR were set as described in Table 3.

Table 1. PCR primer sequences.
\begin{tabular}{ll}
\hline Site & Primer sequence \\
\hline rs6725958 & F: 5'-CTCAGGACTTGGATGGTGTAGA-3' \\
& R: 5'-TCATTTCCCAATAAAAGTACACTG-3' \\
rs10202709 & F: 5'-CAGTCCCAGATCATGGAGTCT-3' \\
& R: 5'-GTACCATGTTACTTGTGGAATAGAG-3' \\
rs35343655 & F: 5'-ACTGAAGTGCTCGGGATGAT-3' \\
& R: 5'-CAGGAACGAAATGTTGGATG-3'
\end{tabular}

$\mathrm{F}=$ forward primer; $\mathrm{R}=$ reverse primer.

\section{Table 2. PCR amplification system (15 $\mu \mathrm{L}$ reaction system).}

\begin{tabular}{lc}
\hline Composition & Volume $(\mu \mathrm{L})$ \\
\hline Ultrapure water & 11.0 \\
2X PCR Mix & 3.1 \\
Primer: forward & 0.2 \\
$\quad$ reverse & 0.2 \\
Template DNA & 0.5 \\
Total volume & 15.0 \\
\hline
\end{tabular}

dNTP (10 mM).

Table 3. PCR amplification conditions.
\begin{tabular}{lccc} 
& & \\
\hline Step & Temperature $\left({ }^{\circ} \mathrm{C}\right)$ & Time & Cycle number \\
\hline Pre-degeneration & 95 & $5 \mathrm{~min}$ & $40 \mathrm{cycles}$ \\
Degeneration & 95 & $30 \mathrm{~s}$ & $345 \mathrm{~s}$ \\
Annealing & 68 & $60 \mathrm{~s}$ & 1 cycle \\
Extension & 72 & $6 \mathrm{~min}$ & $\rightarrow \infty$ \\
Terminal extension & 72 & 4 & \\
Storage & 4 & & \\
\hline
\end{tabular}




\section{Statistical analysis}

The polymorphism allele frequencies were found to be consistent with Hardy-Weinberg equilibrium. Genotypes, differences in genotype frequency distribution, and the correlation of specific genotypes with the occurrence and development of calcium oxalate stones were analyzed by the chi-squared test. The measurement data was expressed as mean \pm standard deviation (SD). All data was analyzed on the SPSS software platform (v.17.0; SPSS Inc., Chicago, IL, USA). $P$ value $<0.05$ was considered to be statistically significant.

\section{RESULTS}

\section{Genotype detection}

The PCR analyses revealed the presence of polymorphisms at the specific sites rs6725958 (mutant A/A (256 bp), wild type C/C (171, 85 bp), and heterozygote A/C (256, 171, 85 bp) phenotypes were obtained; Figure 1), and rs10202709 (mutant T/T (202 bp), wild type C/C (134 and 68 bp), and heterozygote C/T (202, 134, 68 bp) phenotypes; Figure. 2) following digestion with the restriction enzyme Haelll, and at the site rs35343655 (mutant G/G (139, $97 \mathrm{bp}$ ), wild type A/A (236 bp), and heterozygote A/G (236, 139, and $97 \mathrm{bp}$; Figure 3) following digestion with the restriction enzyme $\mathrm{Mspl}$.

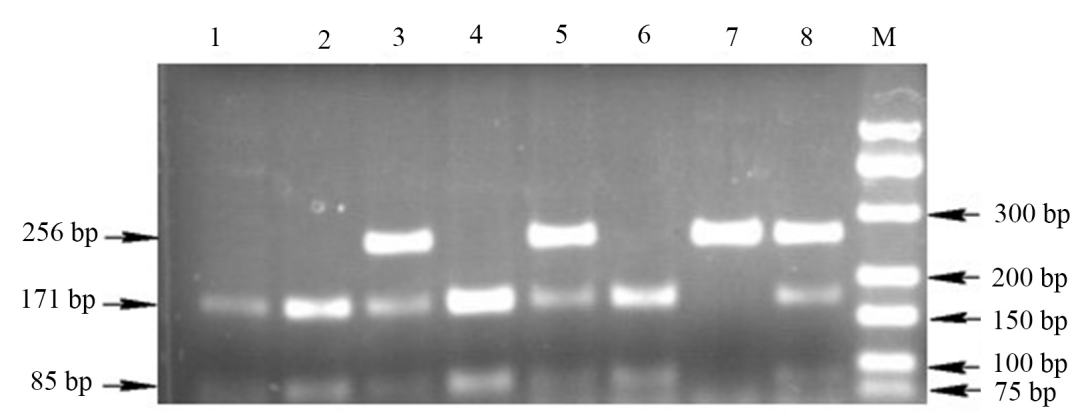

Figure 1. Genotyping of the rs 6725958 polymorphism site in the Fn gene.

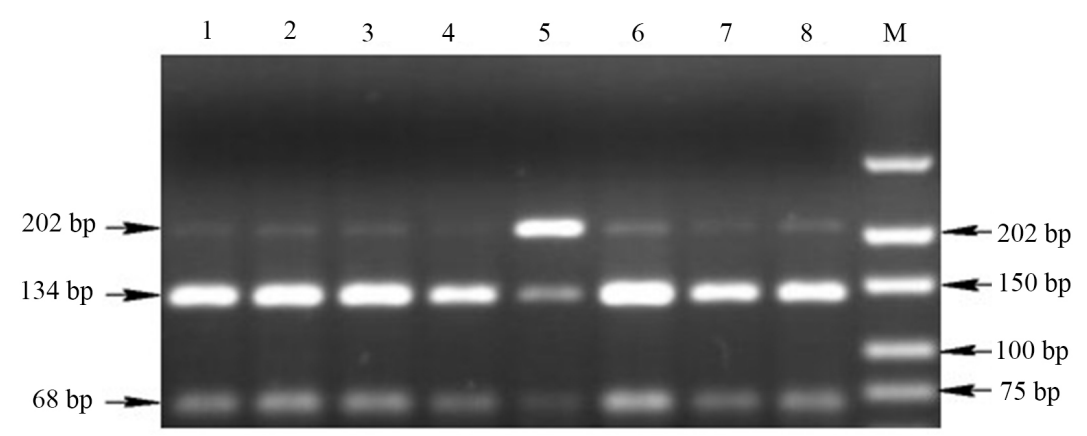

Figure 2. Genotyping of the rs 10202709 polymorphism site in the Fn gene. 


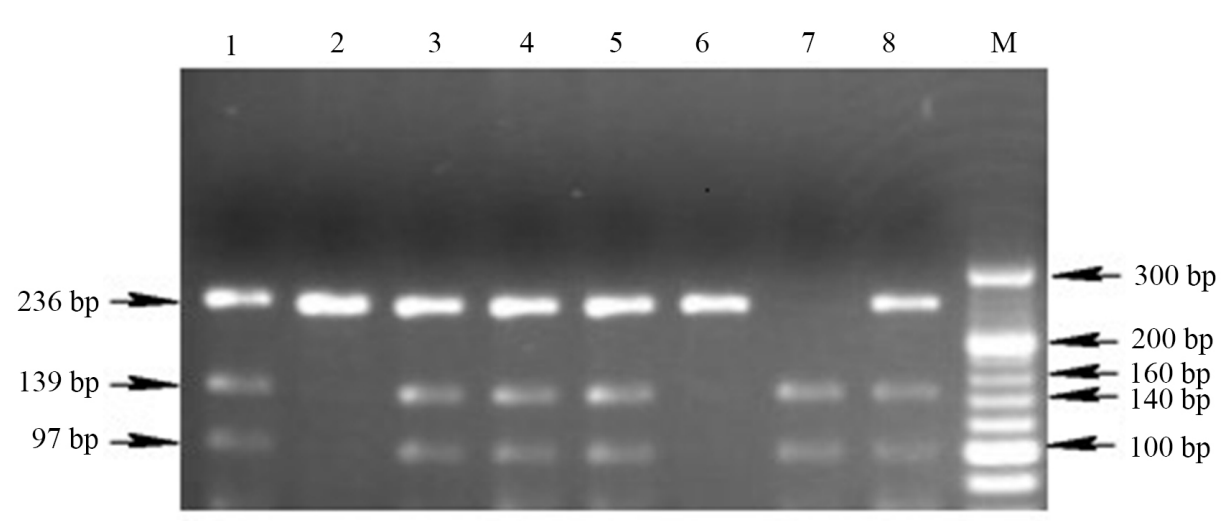

Figure 3. Genotyping of the rs 35343655 polymorphism site in the Fn gene.

\section{Comparison of genotype and allele frequency}

The distribution of genotype and gene frequency of the SNPs rs6725958, rs10202709, and rs35343655 was consistent with the Hardy-Weinberg equilibrium. No significant differences were observed between the genotype and allele frequencies of cases and controls (Tables 4, 5 , and 6).

Table 4. Phenotypes resulting from SNPs in the polymorphism site rs6725958 of the Fn gene.

\begin{tabular}{|c|c|c|c|c|c|}
\hline Subjects & Cases $(N=128)$ & Control $(\mathrm{N}=94)$ & OR & $95 \% \mathrm{Cl}$ & $P$ value \\
\hline \multicolumn{6}{|l|}{ Genotype (\%) } \\
\hline $\mathrm{C} / \mathrm{C}$ & $64(50.00)$ & $36(38.30)$ & 1 & - & \\
\hline $\mathrm{A} / \mathrm{C}$ & $51(39.84)$ & $47(50.00)$ & 1.638 & $0.927-2.894$ & 0.088 \\
\hline $\mathrm{A} / \mathrm{A}$ & $13(10.16)$ & $11(11.70)$ & 1.504 & $0.611-3.703$ & 0.373 \\
\hline $\mathrm{A} / \mathrm{C}+\mathrm{A} / \mathrm{A}$ & $64(50)$ & $58(61.70)$ & 1.611 & $0.938-2.768$ & 0.083 \\
\hline Allele frequency (\%) & & & 1 & - & \\
\hline C & $179(69.92)$ & $119(63.30)$ & & & \\
\hline A & $77(30.08)$ & $69(6.70)$ & 1.348 & $0.904-2.009$ & 0.142 \\
\hline
\end{tabular}

$\mathrm{OR}=$ odd's ratio; $\mathrm{Cl}=$ confidence interval.

Table 5. Phenotypes resulting from SNPs in the polymorphism site rs 10202709 of the Fn gene.

\begin{tabular}{lcccc}
\hline Subjects & Cases $(\mathrm{N}=128)$ & Control $(\mathrm{N}=94)$ & OR & $95 \% \mathrm{Cl}$ \\
\hline Genotype (\%) & $117(91.41)$ & $82(87.23)$ & 1 & - \\
$\mathrm{C} / \mathrm{C}$ & $11(8.59)$ & $12(12.77)$ & 1.557 & $0.655-3.699$ \\
$\mathrm{C} / \mathrm{T}$ & $0(0)$ & $0(0)$ & - & 0 \\
$\mathrm{~T} / \mathrm{T}$ & $11(8.59)$ & $12(12.77)$ & 1.557 & $0.655-3.699$ \\
$\mathrm{C} / \mathrm{T}+\mathrm{T} / \mathrm{T}$ & $245(95.70)$ & $176(93.62)$ & 1 & - \\
Allele frequency (\%) & $11(4.30)$ & $12(6.38)$ & 1.519 & 0.313 \\
$\mathrm{C}$ & & & 0.313 \\
$\mathrm{~T}$ & & & & 0.327 \\
\hline $\mathrm{OR}$ & & & &
\end{tabular}

$\mathrm{OR}=$ odd's ratio; $\mathrm{Cl}=$ confidence interval. 


\begin{tabular}{|c|c|c|c|c|c|}
\hline Subjects & Cases $(N=128)$ & Control $(\mathrm{N}=94)$ & OR & $95 \% \mathrm{Cl}$ & $P$ value \\
\hline \multicolumn{6}{|c|}{ Genotype (\%) } \\
\hline $\mathrm{A} / \mathrm{A}$ & $42(32.81)$ & $20(21.28)$ & 1 & - & \\
\hline $\mathrm{A} / \mathrm{G}$ & 55 (42.97) & $47(50.00)$ & 1.795 & $0.928-3.471$ & 0.081 \\
\hline G/G & $31(24.21)$ & $27(28.72)$ & 1.829 & $0.871-3.839$ & 0.109 \\
\hline$A / G+G / G$ & $86(67.18)$ & 74 (78.72) & 1.807 & $0.795-3.347$ & 0.058 \\
\hline \multicolumn{6}{|c|}{ Allele frequency (\%) } \\
\hline A & $139(54.30)$ & $87(46.28)$ & 1 & - & \\
\hline G & $117(45.70)$ & 101 (53.72) & 1.739 & $0.945 \sim 2.012$ & 0.095 \\
\hline
\end{tabular}

$\mathrm{OR}=$ odd's ratio; $\mathrm{Cl}=$ confidence interval.

\section{DISCUSSION}

Currently, genes polymorphism analyses have seen increased usage in the study of the molecular mechanism of calcium oxalate stones, and has been applied to discover the relationship between the occurrence of calcium oxalate stones and polymorphisms in the $\mathrm{y}$-hydroxybenzyl thiocyanide glutamic acid, vitamin D receptor, and calcitonin receptor genes, among others (Bid et al., 2005; Gao et al., 2007; Metin et al., 2009). Patel and Lodish (1987) mapped the Fn gene to chromosome 2q34-36, and reported the presence of 50 exons. A majority of these exons corresponded to the repeat sequences of peptide chains. RFLP analysis, using the HindIII, Haelllb, Taqla, Taqlb, Mspl, and Haellla enzymes, helped confirm the presence of 6 genotypes. A number of studies have attempted to elucidate the relationship between the Fn gene and tumor susceptibility, metastasis, bone tissue mineralization, damage repair, liver and pulmonary fibrosis, and end-stage renal disease, among others. Tsujihata et al. $(2000,2001,2006)$ reported that $F n$ significantly inhibited the growth and aggregation of calcium oxalate crystals in vitro; in addition, this gene was believed to impart the ability of forming a biofilm on the surface of calcium oxalate crystals, subsequently inhibiting the calcium oxalate crystal-biofilm combination using renal tubular epithelial cells (Tsujikawa et al., 2007; Tsujihata, 2008). Okada et al. (2010), on the other hand, reported that the inhibition of $F n$ in calcium oxalate crystal-forming animal models induced migration, phagocytosis, and digestion of monocytes and macrophages on calcium oxalate crystals, as a result of the interaction between $\mathrm{Fn}$ and CD44.

Three polymorphism sites in the Fn gene (SNPs rs6725958, rs10202709, and rs35343655) were mapped in this study. The genotype and gene frequency distributions of all three were consistent with the Hardy-Weinberg equilibrium in both the case and control groups, which indicated that the samples could be representative of the Uighur population residing in the Xinjiang area of China. The results revealed the absence of any imbalance between the sites. No significant difference was observed in the risk analysis between the genotype, allele, and occurrence of calcium oxalate stones (Tables 4,5 , and 6).

Onaran et al. (2009), in a study involving 143 patients with calcium oxalate nephrolithiasis and 154 healthy volunteers, discovered that polymorphisms in the HindIII restriction site of the $F n$ gene were significantly related to the development of calcium oxalate stones. However, a thorough comparison of the cases and controls revealed the absence of any significant differences the genotype and allele frequency in the three $F n$ sites (rs6725958, rs10202709, and rs35343655) in this study. This indicated that polymorphisms in the rs6725958, rs10202709, and rs35343655 sites of the Fn gene were not representative of the risk factors for the incidence of calcium oxalate stones in the Uighur population of the Xinjiang region of China. This study revealed significant 
differences between susceptibility genes, based on the race of the study subjects, methods of analysis, and sample size; this indicates the need for further research in this field. Therefore, the results of this study could not explain the effect of $F n$ in the formation of calcium oxalate stones in patients belonging to the Uighur population of Xinjiang, China.

Gene polymorphisms occurring at the three SNP sites in the Fn gene were analyzed in this study; however, more relevant clinical data must be collected, the genotype-phenotype relationship must be further analyzed (statistically; with an expanded sample size and between different races), for further confirmation and elucidation of the results obtained in this study. The distribution of polymorphisms in the three sites in the Fn gene must also be carefully analyzed in order to determine the effect of polymorphisms on the development of calcium oxalate stones in urinary calculi patients.

\section{Conflict of interest}

The authors declare no conflict of interest.

\section{ACKNOWLEDGMENTS}

Research supported by funds provided by the Natural Science Foundation of Xinjiang Uighur Autonomous Region (\#201211A048).

\section{REFERENCES}

Brikowski TH, Lotan Y and Pearle MS (2008). Climate-related increase in the prevalence of urolithiasis in the United States. Proc. Natl. Acad. Sci. U. S. A. 105: 9841-9846.

Bid HK, Chaudhaery H and Mittal RD (2005). Association of vitamin-D and calcittonin receptor gene polymorphism in paediatric nehprolithiasis. Paediatr. Nephrol. 20: 773-776.

Deng YL, Ye ZQ and Li CY (2009). The research status of calcium oxalate nephrolithiasis: problems and direction. Chin. J. Surg. 47: 241-243.

Gao B, Yasui T, Itoh Y, Tozawa K, et al. (2007). A polymorphism of matrix Gla protein gene is associated with kidney stone. J. Urol. 177: 2361-2365.

Okada A, Yasui T, Fujii Y, Niimi K, et al. (2010). Renal macrophage migration and crystal phagocytosis via inflammatory-related gene expression during kidney stone formation and elimination in mice: Detection by association analysis of stone-related gene expression and microstructural observation. J. Bone Miner. Res. 25: 2701-2711.

Onaran M, Yilmaz A, Sen I, Ergun MA, et al. (2009). Heparan sulfate gene polymorphism in calcium oxalate nehprolithiasis. Urol. Res. 37: 47-50

Onaran M, Yilmaz A, Sen I, Ergun MA, et al. (2009). A Hindlll polymorphism of fibronectin gene is associated with nephrolithiasis. Urology 74: 104-107.

Patel VP and Lodish HF (1987). A fibrionectin matrix is required for differentiation of murine erythroloukemia cell into reticuh, cytes. J. Cell Biol. 1105: 3105-3118.

Soucie JM, Thun MJ, Coates RJ, McClellan W, et al. (1994). Demographic and geographic variability of kidney stones in the United States. Kidney Int. 46: 893-899.

Tsujihata M, Miyake O, Yoshimura K, Kakimoto KI, et al. (2000). Fibronectin as a potent inhibitor of calcium oxalate urolithiasis. J. Urol. 164: 1718-1723.

Tsujihata M, Miyake O, Yoshimura K, et al. (2001). Comparison of fibronectin content in urinary macromolecules between normal subjects and recurrent stone formers. Eur. Urol. 40: 458-462.

Tsujihata M, Yoshimura K, Tsujikawa K, Tei N, et al. (2006). Fibronectin inhibits endocytosis of calcium oxalate crystals by renal tubular cells. Int. J. Urol. 13: 743-746.

Tsujikawa K, Tsujihata M, Tei N, Yoshimura K, et al. (2007). Elucidation of the mechanism of crystal-cell interaction using fibronectin-overexpressing Madin-Darby canine kidney cells. Urol. Int. 79: 157-163.

Tsujihata M (2008). Mechanism of calcium oxalate renal stone formation and renal tubular cell injury. Int. J. Urol. 15: 115-1120. Worcester EM and Coe FL (2010). Calcium kidney stones. N. Engl. J. Med. 363: 954-963. 